\title{
A ECOSSONDAGEM PESQUEIRA NO LITORAL DO RIO GRANDE DO SUL (*)
}

\author{
LUIZ PAULO RODRIGUES CUNHA \\ Base Oceanográfica A tiantica, Fandaçüo Universidade de Rio Grande \\ Rio Grande, RS, Brasil
}

\section{SYNOPSIS}

In the present paper the echo-sounding use accomplished by fishery boats for demersal species in the Rio Grande do Sul littoral is arscussed. Considerations on the best use are made, including the need of more adequate echo-sounders and the training of the skeepers in echosounding techniques.

Introauçấ

A maior produção de peixes demersais capturados na costa do litoral do Rio Grande do Sul procede de uma faixa de mar relatıvamente estreita, que é justamente a que val desde a margem até a isóbata dos $50 \mathrm{~m}$. Essa área de pesca - que apresenta maior produtividade no litoral compreendido entre a barra do Rio Grande e o Chuí - é a principal responsável pelo avastecimento do importante centro comercial e industrial pesqueiro que se localiza na cidade de Rio Grande.

Desde que foi iniciada a pesca comercial de alto-mar na re-. gião, há cerca de 30 anos, a atividade da frota de arrasteiros temse limitado quase que exclusivamente à referida faixa contígua à costa.

A ecossondaquem pesqueira voltada para a deteccão de espécies demersais vem senco feita, na zona, de forma bastante precária a bordo dos arrasteiros. A falta de ecossondas mais apropriadas as necessidades desse tipo de pesca, aliada ao despreparo dos patrōes-de-pesca para operar convenientemente esses instrumentos, tem privado a frota local da oportunidade de realizar capturas mais efetivas e também de forma mais racional.

\section{O Trabalho de Ecossondagem a Bordo} dos Pesqueiros Locais

\section{a) A dotacāo da frota}

Visando um melhor conhecimento sobre as potencialidades da frota comercial que tem base em Rio Grande, em termos de instrumentos hidroacústicos para a localizacão de peixes, procedeuse ao levantamento de todos os aparelhos existentes nas diversas embarcações que a integram (1). As ecossondas foram praticamente o único instrumento hidroacústico encontrado (registraram-se apenas dois sonares). Conforme se poderá ver na Tabela I. cerca de 50\% dos modelos catalogados já não mais sâo produzidos pelos respectivos fabricantes, havendo sido substituídos por modelos mais aprimorados.

\section{b) Procedimentos atuais de ecossonøangem pesqueira}

Como resultado de observações decorrentes de viagens a bordo de pesqueiros locais, e de entrevistas mantidas com patrōesde-pesca e outros profissionais do setor, arrolam-se as seguintes observações concernentes à operação e ao aproveitamento das ecoss. sondas pesqueiras:

1) sãó utilizadas mais como um instrumento de navegação que propriamente como um instrumento auxiliar das pescas, ou seja, têm emprego limitado quase que exclusivamente à indicação de prớfundidade;

2) - funcionamento desses aparelhos, em consequêencia, restringe-se aos breves momentos de tomada periódica de profundidade, quando em navegação. Durante os arrastos, há patrões-depesca que os mantêm em funcionamento, e outros que o fazem apenas naquelas zonas mais acidentadas ou onde sabem da existência de "pegadores";

\section{(*) Contribuição da Base Oceanográfica Atlântica nọ 9}

(1) Incluem-se aqui os barcos com registro em Rio Grande e vários outros que, mesmo registrados em outros portos pesqueiros, operam no litoral do Rio Grande do Sul, seja em caráter permanente ou temporário.
3) as zonas de pesca o a linha de derrota escolhidas para os arrastos så determinadas, geralmente, pela prática e intuição do pa trão-de-pesca. Os dados que a ecossonda poderia fornecer, se mantida em funcionamento ininterrupto, deixam de ser aproveitados;

4) os al tos custos do papel se interpōem como rator limitante ao desejável aproveiitamento das ecossondas;

5) não foram encontradas, a bordo, quaisquer instrucōes escritas sobre a operação, funcionamento e manutenção desses instrumentos;

6) constatou-se uma sub-utilização daqueles modelos de. maiores recursos, devida, essencialmente, ao desconhecimento, por parte dos mestres, guanto às reais possibilidades dos instrumentos de que dispōem:

7) paralelamente a isso, observou- $-\infty$ que o ajuste dos aparethos se faz de forma bastante deficiente, sendo constatada, também, a falta de habilidade dos patrões-de-pesca para a interpretação satisfatória dos ecorregistros.

\section{A Racionalizaçâo do Trabalho de Ecossondagem Pesqueira}

A experiência que se reuniu de trabalhos de ecossondagem feitos na regiâ,o, tanto mediante instrumental pesqueiro como científico, permitem sejam apontadas aqui algumas idéias e observações com vistas ao aproveitamento da ecossonda como um eficiente instrumento auxiliar das pescas :

\section{a) A ecolha de modelos mais adequados}

A falta de conhecimento prévio sobre as potencialidades que possa apresentar uma ecossonda tem sido, ainda, o principal res ponsável pela inapropriada escolha de boa parte desses instrumentos com os quais se tem buscado dotar embarcaçōes pesqueiras.

$\mathrm{E}$ certo que as modernas ecossondas são, geralmente. bastante completas e que vêm sendo cada vez mais aprimoradas. Porém, ao buscar-se eleger um determinado modelo, convém seja sempre levado em conta o tipo (ou os tipos, se for o caso) de pes. $\mathrm{ca}$ a que o barco se vai dedicar.

Destaca-se, desde logo, que, para o caso específico da pesca de arrasto-de-fundo que tem lugar na Região Sul, os modelos ideais de ecossondas seriam aqueles que pudessem permitir a ampliäç̄o dos ecos do fundo. No entanto, satisfazendo ou não a esse requisito, merecem criteriosa consideração aquelas características básicas di. retamente relacionadas com o poder de resoluşão do instrumento, e que são, fundamentalmente, a frequéncia. o comprimento do pul. so e o ganho crono-variável (TVG). Afora isso, dir-se-ia que o apareltho deveria, também, permitir quaisquer das formas de registro fundamentadas no chamado efeito de bloqueio, a saber, registros de tipo linha branca (white line) ou similar (dynaline e grey Une).

Frequência - as ecossondas pesquisas encontraveis no mercado são produzidas dentro de uma variedade relativamente ampla de frequiências, que oscila geralmente entre os 28 e os $200 \mathrm{kH}$ Sabendo-se que com o emprego de baixas freqüências se estará ganhando alcance em detrimento de uma melhor resolução, pode-se concluir que as ecossondaś mais adequadas para a prơspecção ecóica em águas rasas seriam aquelas mais adequadas para a prospeccão ecóica em águas rasas seriam aquelas de freqüências mai altas. Frequêencias compreendidas entre os 150 e os $300 \mathrm{kHz}$ darão ótima resolução em profundidades que vão até os 50 metros. $\hat{E}$ importante notar que há alguns modelos, inclusive, que operam com dupla frequêência, selecionável (p. ex. $50 \mathrm{kHz}$ e $200 \mathrm{kHz}$ ). 
Comprimento do pulso - quanto menor for o comprimento do pulso, maior será a resoluçăo, quando se trata de discriminar peixes prórimo uns dos outros. Sendo que o registro guarda uma relação direta com o cumprimento do pulso, se a distância entre dois peixes é inferior à metade do comprimento do pulso, os ecotraços correspondentes a seus respectivos ecos irão se sobrepor. Sabendo-se que, com uma duração de 1 milisegundo, o comprimento de pulso correspondente é de 1,5 metros, apresentarão melhor performance, para o caso da pesca em evidência, aqueles aparelhos cujo comprimento de pulso é inferior a 1 milisegundo. Convém que se ressalte, também, que muitas das ecossondas atuais possibilitam a seleção de vários comprimentos de pulso (longos e curtos), o que atende satisfatoriamente a essa peculiaridade.

Ganho crono-varidvel (TVG) - várias ecossondas compensam automaticamente a debilitação da força do sinal procedente de alvos mais afastados, mediante o sistema de ganho crono-varifvel (time varied gain). Graças a esse sistema, torna-se possivel a compa. ração de ecos procedentes de distintas profundidades. Atualmente, a maior parte dos modelos incorpora esse recurso.

Linha branca - quando se buscam aquelas espécies de pe1. xes que se ditribuem próximo ao fundo, torna-se muito difícil diferenciar os ecos que delas procedem daqueles provenientes do próprio fundo do mar, se a ecossonda opera sob a forma de registro normal. Isso porque, em que pese os diversos recursos que uma ecossonda possa incorporar para uma maior resolução nos registros, esses recursos mostram-se insuficientes para fazer essa necessária separação. Baseado, porém, no fato de que há uma sensível diferenca na força do sinal refletido pelos peixes e pelo fundo marinho, foi desenvolvido o sistema de registro conhecido como linha bran: $c a$ (white line), que possibilita a distinção entre ambos. Sistemas similares de registro, como o dynaline e o grey line, são também adotados por vários modelos de ecossondas.

Ampliação dos registro do fundo - há, hoje em dia, uma grande variedade de ecossondas que permitem um detalhamento mais amplo dos ecorregistros correspondentes aos últimos metros acima da linha de fundo (inclusive com intervalos selecionáveis), informação esta que se fornece de forma expandída, registrada sobre o mesmo papel registrador. Esse recurso pode estar incorporado ao próprio aparelho ou então pode constituir-se numa unidade suplementar conectável. Em ambos os casos. os registros amplificados são teitos na faixa inferior do papel; na faixa superior, perma nece o registro normal sob escala. Esse recurso, que opera associado às formas de registro white line, dynaline ou grey line, é de relevada imbortância para a pesca de arrasto-de-fundo.

Cábe ser dito, amda, que as lupas de pesca (fish lupe ou fish scope) desempenham uma função análoga (a imagem, igualmente amplificada, é apresentada num tubo de raios catódicos), muito embora o sistema de apresentação anterior - diretamente sobre o papel - tenha logrado, ultimamente, maior popularidade entre os pescadores, pela facilifiade de vísualização e imedrata associação com o ecograma normal.

\section{b) A capacitaçẫo da mão-de-obra embarcada}

Fica claro, desde logo, que não é suficiente proceder-se à boa escolha de uma ecosonda, se a pessoa que a vai operar não está de posse de um perfeito conhecimento sobre a mesma, com vistas a que seu aproveitamento seja feito de forma racional.

Fica assente, de outra parte, que a escolha do aparelho e a capacitação do operador apenas levam à obtenção de registros de boa qualidade; é, no entanto, da eficiente interpretação desses registros que irá depender $\circ$ bom aproveitamento das pescarias.

Para atender a esses imperativos, e dada a importância da pesca de arrasto-de-fundo na regiäo em apreço, a necessidade do engajamento dos órgãos oficiais interessados parece fora de dúvida. Um programa voltado para a capacitação da mâo-de-obra embarcada, em técnicas e procedimentos afetos ao trabalho com ecossondas, acompanhado de um outro com vistas a renovação (quando fosse o caso) desses instrumentos, incrementando a dotação da frota com aparelhos de melhor performance, constituir-seia numa medida bastante oportuna e desejável.

\section{c) 0 papel dos fabricantes e fornecedores}

O empenho por bem assessorar o usuário, as garantias de uma eficiente assistência técnica e o forneciment to de catálogos em idioma pátrio (ou pelo menos das instruçōes sobre a parte operacional e sobre a manutenção afeta ao patrão-de-pesca) já se fazem igualmente oportunos. Essa última medida certamente viria a minorar em muito os problemas do mau aproveitamento das ecossondas em nossos pesqueiros.

\section{Conclusão}

E sábido que os fundos encontrados na plataforma continental do Rio Grande do Sul são predominantemente arenosos e areno-lamosos, o que associado à sua declividade bastante suave, torna praticável a pesca de arrásto-de-fundo na maior parte de sı superfície. No entanto, em predominando esses fundos "moles". e dado o próbrio comportamento das esnécies demersais em si, a detectação desses peixes - cujas pescas säo as mais desenvolvidas na régião - é grandemente prejudicada, seja pelo sub-aproveitamento das ecossondas dotadas de maiores recursos, seia pelas limitações daquelas mais simples ou mesmo inadequadas às condieionantes impostas por esse tipo de pesca, ou, ainda, devido à inabilidade dos patrōes-de-pesca para a operação satisfatória desses anarethos.

A realização de breves cursos de capacitação, repetidos, poderia ser uma promocão relativamente viável. Para tanto, poderse-ia aproveitar a temporada do verão, quando a pesca se reduz sen-

MODELOS DE ECOSSONDAS ENCONTRADOS NAS EMBARCACŌES PESOUEIRAS QUE SE DEDICAM A PESCA DE ARRASTO DE FUNDO NO LITORAL DO RIO GRANDE DO SUL (CADASTRADOS DE ABRIL A AGOSTO DE I978)

\begin{tabular}{|c|c|c|c|c|c|c|c|}
\hline MARCA & MODELO & $\begin{array}{l}\text { APARELHOS } \\
\text { CADASTRADOS }\end{array}$ & $\begin{array}{l}\text { FREQUUÊNCIA } \\
\text { (KHZ) }\end{array}$ & $\begin{array}{c}\text { COMPR. PULSO } \\
\text { (ms) }\end{array}$ & TVG & $\begin{array}{l}\text { LINHA BRANCA } \\
\text { (ou similar) }\end{array}$ & $\begin{array}{c}\text { MENOR ESCALA } \\
(\mathrm{m})\end{array}$ \\
\hline \multirow{6}{*}{ FURUNO } & $F M \quad 22-4$ & 10 & 50 & & & $x$ & $0 \quad 50$ \\
\hline & F-850A MK II & 03 & 50 & 1.5 & $x$ & $x$ & $0-0 i s$ \\
\hline & F- $850 \mathrm{~B}$ MK II & 02 & 50 & 1,5 & $x$ & $x$ & $0-120$ \\
\hline & $F-850 \mathrm{C}$ MKI & 01 & 50 & 1.5 & $x$ & $x$ & 0.80 \\
\hline & F-860 C MKII & 10 & 50 & 1,5 & $x$ & $x$ & 0.80 \\
\hline & $F-8500$ MKII & 03 & 50 & 1.5 & $x$ & $x$ & $0-120$ \\
\hline \multirow{3}{*}{ SIMRAD } & ES & 15 & 38,5 & $1,2 / 2,7$ & - & $x$ & $2-75$ \\
\hline & 160 & 04 & 160 & 0,3 & - & $x(D L)$ & $0-40$ \\
\hline & $E L$ & 04 & 38 & 0,7 & $x$ & $x(D L)$ & $0-50$ \\
\hline \multirow{2}{*}{ ATLAS - WERKE } & $A 28 B C$ & 01 & $9 / 1$ & $s / 1$ & $3 / 1$ & $x$ & 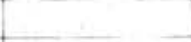 \\
\hline & $A Z 88 E$ & oi & $5 / 1$ & $s / 1$ & $8 / i$ & $x$ & \\
\hline \multirow{2}{*}{ KOOEN } & $S R-385 A$ & 01 & 75 & $0,7(2)$ & $x$ & $x$ & $0-15$ \\
\hline & $S R-658 A$ & 03 & 50 & 0.7031 & $x$ & $x$ & $0-70$ \\
\hline BENMAR & $D R-25$ & 02 & $3 . ?$ & $5 / 1$ & sir & $x$ & D. -50 \\
\hline SPERRY & $S R-3000 R$ & 09 & 5. 3 & $5 / 1$ & $3 / 1$ & $x$ & $0-60$ \\
\hline ELAC & $L V G-3$ & 01 & $3 / 4$ & sil & $x$ & - & $0-75$ \\
\hline JRC & NJA -510 & 01 & 75 & $9 / 1$ & - & - & $0-30$ \\
\hline RAYTHEON & $D E-721 A$ & 01 & $5 / 1$ & $3 / 1$ & $5 / 1$ & $3 / 1$ & 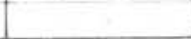 \\
\hline
\end{tabular}


sivelmente na área, para permutir a um major número de profissionais o aproveitamento dessa oportunidade. Como alternativa mais simples - há que se levar em conta que o tempo dos pescadores em terra é mínimo - poder-se-ia editar, como trabalho preliminar, uma espécie de "cartilha" em que fossem apresentados os princípios básicos da ecossondagem, como também a maneira de se operar eficientemente uma ecossonda.

Finalmente, a mcorporação de modelos de ecossondas mais efetivos, apropriadamente utilizados, representaria, seguramente, um grande benencicio para a pesca no litoral do Rio Grande do Sul, ’ois que propiciaria melhores condições para a localização e dimensionamento das concentraçōes de peixes, além de contri- buir sensivelmente para a racionalizaçao das pescarias. Haveria, conseqüentemente, não só uma apreciável redução de custos, como também uma sensível melhoria na qualidade do pescado, resultantes do incremento das capturas e da diminuição do tempo de permanência no mar.

\section{Agradecimento}

Ao Lic. Jorge Pablo Castelo, Supervisor do Núcleo de Avaliação Pesqueira da Base Oceanográfica Atlântica, pela reviš̃o e crítica do presente trabalho. 